\title{
STRATEGI PENINGKATAN MUTU LULUSAN PRODI PAUD MELALUI PELAKSANAAN SISTEM PENJAMINAN MUTU INTERNAL DI UNIVERSITAS ISLAM NUSANTARA
}

\author{
${ }^{1}$ Rifqi Zaeni Achmad Syam, ${ }^{2}$ R. Supyan Sauri, ${ }^{3}$ Rosiana Nurwa Indah \\ 1,2,3 Universitas Islam Nusantara, Bandung, Indonesia \\ e-mail: ${ }^{1}$ rifqisyam@uninus.ac.id, ${ }^{2}$ uyunsupyan@uninus.ac.id, ${ }^{3}$ rosiananurwaindah@uninus.ac.id
}

13002

\begin{abstract}
This study aims to describe the strategy to improve the quality of graduates Prodi early childhood as an effort in improving the quality of education at the Islamic University of Nusantara Bandung. This is very important considering the problems of early childhood is so complex from starting input PAUD students, teachers who have not yet qualified, PAUD institutional management has not met the standards. This study uses a qualitative research approach with case study methods. The research was conducted in Prodi PAUD Universitas Islam Nusantara, with the subject of Quality Assurance Unit (UPM) Prodi PAUD Faculty of Teacher Training and Education. Data collection techniques: direct observation, document tracking and archives, and in-depth interviews.
\end{abstract}

Keywords: SPMI, Quality Assurance, Education Quality

\section{PENDAHULUAN}

Pentingnya peningkatan kompetensi dan profesionalisme guru pendidikan usia dini dapat ditinjau dari beberapa aspek atau dimensi. Sudut pandang pertama, dilihat dari aspek perkembangan ilmu pengetahuan dan teknologi yang sangat pesat, yang berimplikasi pada munculnya metode dan media baru dalam proses belajar mengajar. Demikian pula dengan pengembangan materi ajar dalam rangka pencapaian target kurikulum harus seiring dengan perkembangan ilmu pengetahuan dan teknologi. Fenomena ini harus dikuasi guru dan kepala sekolah pada pendidikan anak usia dini, sehingga berkemampuan mengembangkan proses belajar mengajar yang dapat membawa perserta didik potensial pada perkembangan yang optimal. Selanjutnya ditinjau dari kepuasan pengguna lembaga pendidikan usia dini, peningkatan kompetensi dan profesionalisme guru menjadi keharusan dalam rangka pemenuhan standar mutu layanan pendidikan.
Secara sederhana upaya peningkatan kemampuan profesionalisme dan kompetensi guru bisa diartikan suatu proses membantu calon guru atau guru yang belum komteten diarahkan menjadi guru yang mempunyai kompetensi dan profsional dalam menjalankan perannya sebagai tenaga pendidik. Oleh karena itu peningkatan guru di pendidikan usia dini diarahkan pada pembinaan kemamuan dan sekaligus pembinaan komitmennya.

Urgennya mendidik anak sejak usia dini dengan dilandasi kesadaran pemangku kepentingan, bahwa masa kanak-kanak adalah masa yang paling berharga untuk mencapai masa depan atau generasi penerus bangsa. Kesadaran akan pentingnya pendidikan anak usia dini selama ini mendapatkan perhatian yang cukup baik dari berbagai kalangan masyarakat, pemerintah, pihak swasta, orang tua, dan lain-lain. Hasil dari kepedulian tersebut adalah banyaknya berbagai dari akademis membuat program studi Pendidikan Anak Usia Dini diberbagai Universitas. Namun, tidak selamanya pembangunan 
pendidikan anak usia dini dapat berjalan dengan lancar atau dapat dikatakan belumlah optimal dari kalangan pihak pemerintah, swasta, ataupun masyarakat Indonesia. Pendidikan anak usia dini yang bersifat formal dapat dilakukan melalui Taman Kanak-Kanak dengan biaya pendidikan yang lebih besar dibandingkan dengan pendidikan non formal seperti, kelompok bermain, tempat bermain anak, dll.

Permasalahan lain yang dihadapi dalam pembangunan pendidikan termasuk pendidikan anak usia dini di Indonesia antara lain, kebijakan pemerintah tentang pendidikan anak usia dini di Indonesia yang kurang memadai, kurangnya kesadaran masyarakat Indonesia tentang pentingnya pendidikan anak usia dini, kurangnya mutu dalam pembangunan pendidikan anak usia dini, kurangnya kualitas dan kuantitas para pengajar pendidikan anak usia dini, beberapa lembaga pendidikan anak usia dini di Indonesia belum mengajarkan mengenai kecerdasan intelektual, belum tercapainya kebutuhan masyarakat Indonesia anak program pendidikan anak usia dini.

Sementara dari sisi lembaga perguruan tinggi sebagai sarana fomal dalam menyiapkan sumber daya manusia yang unggul dan profesional masih dihadapkan pada berbagai kendala. Kondisi pendidikan Tinggi di Indonesia yang berpopulasi 255 juta dewasa ini perlu mendapatkan perhatian khusus. Berdasarkan data FORLAP DIKTI (PD-DIKTI): Jumlah perguruan tinggi 4.514. Berbentuk universitas sebanyak 3121, akademi 1108, politeknik 262, akademi komunitas 12 dan PTN-BH 11. Jumlah total dosen yang ada 200.175 orang. Dari jumlah tersebut hanya kurang lebih $10 \%$ yang bergelar S3. Jumlah total mahasiswa sekitar 7 juta orang. Dari jumlah ini sebanyak 240.000 orang menempuh jalur Vokasi/Politeknik. Ketimpangan mutu Perguruan Tingggi dapat dilihat dari data yaitu: mayoritas institusi dan prodi terakreditasi $\mathrm{C}$ (BAN-PT), dan sedikit prodi terakreditasi internasional (ABET, AACSB,AUN-QA, dsb). Dengan Sistem pendidikan tinggi yang bermutu dapat berimplikasi dalam menghasilkan sumber daya manusia dengan basis intelektual, ilmuwan, atau profesional yang beriman bertaqwa, berakhlaq mulia, berbudaya, kreatif, berkarakter tangguh, serta karya Penelitian untuk kemaslahatan bangsa, negara, dan manusia dan juga kegiatan Pengabdian Kepada Masyarakat. Terdapat disparitas kualitas pendidikan tinggi antara yang berada di pulau jawa dengan yang berada di luar Jawa.

Universitas Islam Nusantara merintis dan mengembangkan konsep sistem penjaminan mutu internal (SPMI) perguruan tinggi sejak tahun 2009. Konsep tersebut meliputi definisi penjaminan mutu, siklus Penerapan penjaminan mutu, organisasi, sistem dokumentasi, dan sumber daya manusia. SPMI di Universitas Islam Nusantara dilakukan oleh Direktorat Penjaminan Mutu (DPM) yang bertugas merencanakan, mengorganissikan, melaksanaan, dan mengevaluasi sistem jaminan mutu secara keseluruhan di Universitas Islam Nusantara.

Penerapan sistem penjaminan mutu pendidikan di perguruan tinggi merujuk pada Pedoman Penjaminan Mutu (Quality Assurance) Pendidikan Tinggi (2003: 16-19) SPMI dapat dilaksanakan, bila terpenuhi beberapa prasyarat, yaitu: komitmen, perubahan paradigma, dan sikap mental para pelaku proses pendidikan tinggi, serta pengorganisasian penjaminan mutu di perguruan tinggi. Penerapan sistem penjaminan mutu di perguruan tinggi sering menemui kendala/hambatan di lapangan antara lain; tingkat kesadaran para pelaku proses pendidikan tentang arti penting penjaminan mutu sebagai kebutuhan stakeholders masih belum optimal, komitmen stakeholders internal pendidikan tinggi untuk menjamin dan meningkatkan mutu pendidikan masih kurang, pemahaman terhadap konsep dan Penerapan SPMPT oleh pelaku pendidikan tinggi belum merata, tata kelola dan mekanisme kerja penjaminan mutu belum terbangun dengan secara utuh, upaya pemberdayaan sumber daya manusia khususnya bagi para dosen dalam mendukung sistem penjaminan mutu internal belum 
optimal, dan pemanfaatan teknologi informasi dan komunikasi untuk mendukung sistem penjaminan mutu internal belum optimal.

Universitas Islam Nusantara merupakan salah satu universitas tertua di Jawa Barat berdiri sejak tahun 1959. Konsep dan Penerapan Sistem Penjaminan Mutu Perguruan Tinggi di Universitas Islam Nusantara telah dibuat dan disosialisasikan kepada seluruh pimpinan, dosen, mahasiswa, dan tenaga kependidikan pada tingkat universitas dan fakultas dan program studi. Keberhasilan Penerapan SPMI di Universitas Islam Nusantara tidak lepas dari peran serta seluruh sivitas akademika dalam mendukung kegiatan penjaminan mutu internal untuk memenuhi kepuasan stakeholders. Meskipun demikian, beberapa kendala masih ditemui dalam Penerapan SPMI di Universitas Islam Nusantara.

Penerapan SPMI di perguruan tinggi sering menemui masalah, antara lain: (1) kesadaran para pelaku proses pendidikan terhadap arti penting penjaminan mutu sebagai kebutuhan stakebolders relatif masih rendah; (2) pemahaman konsep sistem penjaminan mutu pendidikan oleh stakeholders internal untuk meningkatkan mutu pendidikan masih belum merata; (3) komitmen para pelaku proses pendidikan tinggi di perguruan tinggi, baik yang memimpin maupun yang dipimpin untuk senantiasa menjamin dan meningkatkan mutu pendidikan relatif masih kurang; (4) Ketersediaan sumber daya manusia khususnya tenaga auditor untuk mendukung SPMI masih belum terpenuhi; dan (5) Penerapan SPMI sering menjadi sebuah rutinitas menyebabkan sulit untuk mengukur ketercapaian perbaikan berkelanjutan.

Penelitian ini bertujuan untuk mengetahui Penerapan sistem penjaminan mutu internal dalam upaya penguatan tatakelola program studi di Universitas Islam Nusantara dalam hal ini Program Studi Pendidikan Anak Usia Dini. Secara spesifik, penelitian ini bertujuan untuk: mendeskripsikan penerapan penjaminan mutu internal pada Program Studi Pendidikan Anak Usia Dini, juga secara keseluruhan di
Universitas Islam Nusantara, melalui proses evaluasi serta pemanfaatan hasil penerapan sistem penjaminan mutu internal dalam rangka penguatan tatakelola program studi secara berkelanjutan di Universitas Islam Nusantara.

Oakland (1993: 5) menyatakan bahwa "Quality is used to signify 'excelence' of a product or service". Mutu digunakan untuk menunjukkan keunggulan dari sebuah produk atau jasa. Suatu produk atau jasa dikatakan bermutu apabila mempunyai keunggulan dibanding produk atau jasa yang lain. Macdonald (2005: 6) menyatakan "A useful definition is, 'quality means conformance to requirements'. That allows us to measure quality. We know when we do or do not conform to requirements". Mutu berarti kesesuaian dengan persyaratan. Persyaratan yang memungkinkan untuk mengukur kualitas dengan mengetahui bahwa sesuatu itu memenuhi syarat tertentu untuk dikatakan berkualitas. Tjiptono \& Diana (2000: 2) menyatakan: "Konsep kualitas itu sendiri sering dianggap sebagai ukuran relatif kebaikan suatu produk atau jasa yang terdiri atas kualitas desain dan kualitas kesesuaian. Kualitas desain merupakan fungsi spesifikasi produk, sedangkan kualitas kesesuaian adalah suatu ukuran seberapa jauh suatu produk memenuhi persyaratan atau spesifikasi kualitas yang telah ditetapkan". Pengertian mutu secara garis besar adalah gambaran dan karakteristik menyeluruh dari produk atau jasa yang menunjukkan kemampuannya dalam memenuhi kebutuhan, harapan, dan kepuasan pelanggan proses perencanaan, penerapan, serta kendala yang dihadapi dalam pelaksanaan sistem Orientasi terhadap mutu membutuhkan sistem penjaminan mutu agar mutu dapat ditingkatakan secara berkelanjutan. Sistem penjaminan mutu (Quality Assurance System) dalam suatu institusi pendidikan merupakan tuntutan eksternal dan internal. Sesuai Undang-Undang Nomor 20 Tahun 2003 disebutkan bahwa pengelolaan satuan pendidikan tinggi dilaksanakan berdasarkan prinsip otonomi, akuntabilitas, jaminan mutu, dan evaluasi yang transparan. Lebih jauh, dalam Undang-undang Nomor 12 Tahun 2012 pasal 52 dinyatakan bahwa 
penjaminan mutu pendidikan tinggi merupakan kegiatan sistemik untuk meningkatkan mutu pendidikan tinggi secara berencana dan berkelanjutan.

Hedwig \& Polla (2006: 1-3) menjelaskan bahwa penjaminan mutu merupakan pekerjaan rutin yang berkesinambungan dan harus terus menerus dilakukan dan bukan merupakan kegiatan yang bersifat ad hoc. Oleh karenanya, proses pengawasan (monitoring) dan evaluasi perlu diterapkan secara terus menerus dengan penekanan bahwa kegiatan ini bukan mencaricari kesalahan melainkan untuk melakukan tindakan perbaikan secara terus menerus. Sistem penjaminan mutu (quality assurance system) akan menghasilkan lulusan perguruan tinggi yang baik, kreatif, inovatif dan mampu menciptakan lapangan kerja dengan ilmu pengetahuan dan teknologi yang dimilikinya yang merupakan indikator keberhasilan dari pendidikan tinggi yang bermutu. Sistem penjaminan mutu pendidikan adalah sistem yang dirancang untuk meningkatkan mutu pendidikan secara terprogram dan berkelanjutan melalui tahap penetapan, pelaksanaan, evaluasi, pengendalian, dan peningkatan standar pendidikan. Sistem penjaminan mutu (quality assurance system) digunakan untuk menghasilkan lulusan yang mampu mengembangkan ilmu pengetahuan dan teknologi sebagai indikator keberhasilan dari pendidikan yang bermutu.

Konsep Total Quality Management (TQM) digunakan sebagai pendekatan untuk meningkatkan mutu, daya saing, efektivitas dan fleksibelitas dari keseluruhan organisasi. TQM adalah sistem manajemen yang fokus pada orang yang bertujuan untuk meningkatkan kepuasan pelanggan dengan pengeluaran biaya yang rendah. Macdonald (2005: 6) menyatakan bahwa "TQM is therefore a change agent which is aimed at providing a customerdriven organisation". TQM adalah agen perubahan yang ditujukan untuk mengarahkan organisasi agar berorientasi pelanggan. Dengan demikian semua aktivitas dalam organisasi ditujukan untuk memenuhi kebutuhan dan kepuasan pelanggan. Total Quality Management tidak bekerja untuk kepentingan orang lain, tetapi fokus pada kepentiangan pelanggan. Pemahaman ini tidak hanya diperuntukkan bagi manajer senior saja, melainkan untuk semua orang yang ada dalam organisasi.

Karakteristik dari sistem penjaminan mutu adalah mengembangkan dan mengadopsi standar dan tingkat kinerja minimum terhadap mutu yang dapat dinilai. Ada dua aspek yang saling terkait standar, yaitu dampak layanan pendidikan tinggi terhadap komunitas lokal, dan standar kualitas teknis program yang ditawarkan. (Worthen \& Berry 2002: 1-2) menyatakan bahwa definisi kualitas dalam pendidikan tinggi mencakup perhitungan tingkat kelulusan dan total mahasiswa, tingkat penyerapan alumni dalam pekerjaan dan tingkat upah, tingkat penempatan mahasiswa dalam pendidikan lanjut, skor dan standar tes, penggunaan sumber daya yang efisien, pelaporan dan pertanggungjawaban tertulis tepat waktu, aksesibilitas pendidikan untuk semua orang, ukuran kelas dan rasio dosen dan mahasiswa, evaluasi berdasarkan pengajaran, pengembangan kemampuan mahasiswa untuk menerapkan praktik pembelajaran baru, dorongan dan fasilitasi dalam pembelajaran sepanjang hayat, kesempatan pengembangan profesional untuk dosen, kegunaan pembelajaran untuk mahasiswa, pengembangan keterampilan dan kebiasaan aktif sebagai warganegara, pengembangan kesadaran kritis, penciptaan kebersamaan, lingkungan pembelajaran yang saling menghormati dan timbal balik di kalangan mahasiswa dan dosen, dan jaminan kebebasan akademik untuk diskusi bagi mahasiswa dan dosen.

Penerapan sistem penjaminan mutu perguruan tinggi harus didukung oleh ketersediaan data dan informasi tentang perguruan tinggi secara akurat, lengkap, dan mutakhir. Data dan informasi tersebut dikelola oleh suatu pangkalan data pada masingmasing perguruan tinggi. Hasil pelaksanaan penjaminan mutu internal oleh masingmasing perguruan tinggi merupakan bahan dalam pelaksanaan penjaminan mutu eksternal atau akreditasi oleh BAN-PT 
dan/atau lembaga mandiri lainnya yang diakui pemerintah.

Sistem Penjaminan Mutu Internal (SPMI) adalah kegiatan sistemik penjaminan mutu pendidikan tinggi di perguruan tinggi oleh perguruan tinggi (internally driven), untuk mengawasi penyelenggaraan pendidikan tinggi oleh perguruan tinggi secara berkelanjutan (continuous improvement). SPMI merupakan kegiatan mandiri dari perguruan tinggi yang bersangkutan, sehingga proses tersebut dirancang, dijalankan, dan dikendalikan sendiri oleh perguruan tinggi yang bersangkutan tanpa campur tangan dari pemerintah. SPMI dijalankan oleh perguruan tinggi secara internal untuk mewujudkan visi dan misi-nya, serta untuk memenuhi kebutuhan stakeholders melalui penyelenggaraan Tridharma Perguruan Tinggi. Konsep SPMI, seperti dikemukakan dalam Kemendiknas (2010: 17), suatu perguruan tinggi dinyatakan bermutu apabila: perguruan tinggi mampu menetapkan dan mewujudkan visinya; perguruan tinggi mampu menjabarkan visinya ke dalam sejumlah standar dan standar turunan; perguruan tinggi mampu menerapkan, mengendalikan; mengembangkan sejumlah standar dan standar turunan dalam butir untuk memenuhi kebutuhan stakeholders. Pedoman Penjaminan Mutu (Quality Assurance) Pendidikan Tinggi (2003 :16-18) lebih lanjut menyebutkan bahwa penerapan SPMI di perguruan tinggi memerlukan persyarat agar dapat mencapai tujuannya, yaitu: Komitmen, Sikap Mental, Pengorganisasian. Penyamaan visi dan persepsi kepada sivitas akademika terutama dosen dan tenaga kependidikan untuk selalu merencanakan semua pekerjaan untuk mendukung pencapaian tujuan. Perencanaan terhadap pekerjaan ini sangat penting sebagai kerangka kerja untuk mengukur keberhasilan kerja, sehingga peningkatan mutu secara berkelanjutan dapat terwujud. Pada sisi yang lain, keberhasilan Penerapan SPMI juga perlu didukung dengan organisasi SPMI yang kuat dengan independensi yang dimiliki untuk melakukan penjaminan mutu pendidikan melalui kegiatan penjaminan mutu internal. Organisasi SPMI diharapkan mampu menumbuhkan sikap suportif dari seluruh komponen di perguruan tinggi itu terhadap upaya penjaminan mutu pendidikan Sistem Penjaminan Mutu Eksternal (SPME) adalah kegiatan sistemik penilaian kelayakan program dan/atau perguruan tinggi oleh Badan Akreditasi Nasional Perguruan Tinggi (BANPT) atau lembaga mandiri di luar perguruan tinggi yang diakui pemerintah, untuk mengawasi penyelenggaraan pendidikan tinggi untuk dan atas nama masyarakat sebagai bentuk akuntabilitas publik. Keberadaan BAN-PT diatur dalam Peraturan Pemerintah Nomor 19 Tahun 2005 Pasal 1 butir 27, yang menyatakan: "Badan Akreditasi Nasional Perguruan Tinggi yang selanjutnya disebut BAN-PT adalah badan evaluasi mandiri yang menetapkan kelayakan program dan/atau satuan pendidikan pada jenjang pendidikan tinggi dengan mengacu pada Standar Nasional Pendidikan".

Pemantauan atau penjaminan eksternal mencakup berbagai evaluasi kualitas yang dilakukan oleh individu atau lembaga eksternal untuk lembaga pendidikan tinggi, termasuk akreditasi di tingkat kelembagaan dan program penilaian pengajaran dan kualitas penelitian, audit atau review terhadap prosedur kelembagaan dan pemantauan standar. Esensi dari SPME atau akreditasi adalah penilaian kelayakan dan penjaminan mutu perguruan tinggi atau program studi yang dilakukan oleh organisasi atau badan independen di luar perguruan tinggi (external quality review). Dalam pelaksanaan SPME, mutu perguruan tinggi/program studi merupakan totalitas keadaan dan karakteristik input, proses, dan output atau layanan yang diukur dengan SNP yang menentukan dan mencerminkan mutu Perguruan Tinggi/Program Studi yang bersangkutan.

\section{METODE PENELITIAN}

Penelitian ini mengunakan pendekatan kualitaif dengan metode studi kasus. Menurut Yin (2013: 1), studi kasus merupakan strategi yang lebih cocok digunakan untuk penelitian yang pokok pertanyaan penelitiannya berkenan dengan how atau whay. Selain itu, 
studi kasus digunakan bila peneliti hanya memiliki sedikit peluang untuk mengontrol peristiwa-peristiwa yang diselidiki, dan bila fokus penelitin terletak pada fenomena kontemporer (masa kini) di dalam konteks kehidipan nyata. Pada penelitian ini, kasus yang diteliti adalah Penerapan Sistem Penjaminan Mutu Internal (SPMI) pada Program Studi Pendidikan Usia Dini di Universitas Islam Nusantara. Disisi lain masih banyak program studi yang belum melaksanakan sistem penjaminan mutu internal secara optimal.

Penelitian ini dilaksanakan di Direktorat Penjaminan Mutu (DPM), GPM dan UPM Universitas Islam Nusantara. Adapun pelaksanaan penelitian dimulai bulan Maret 2018 sampai dengan bulan Juni 2018. Target atau subjek penelitian ini adalah Direktorat Penjaminan Mutu (DPM), Gugus Penjaminan Mutu (GPM) FKIP dan Unit Penjaminan Mutu (UPM) Program Studi Pendidikan Usia Dini Universitas Islam Nusantara beserta keseluruhan bagian dan personal yang terlibat dalam kegiatan penjaminan mutu internal di Universitas Islam Nusantara, diambil dari pimpinan DPM, GPM dan UPM , beserta staf. Objek penelitian ini Penerapan Sistem Penjaminan Mutu Internal (SPMI) oleh UPM dan Program Studi Pendidikan Usia Dini yang melipui, kebijakan, tujuan dan sasaran UPM. Kebijakan dan konsep Sistem Penjaminan Mutu Internal (SPMI) meliputi Penetapan Standar, Pelaksanaan Standar, Evaluasi Standar, Pengendalian Standar dan Peningkatan Standar.

Data yang dikumpulkan dalam penelitian ini berupa data kualitatif yang berasal dari hasil pengumpulan data dengan mengunakan teknik pngumpulan data yang sudah disiapkan. Instrumen pengmpulan data dalam penelitian kualitatif adalah peneliti sendiri. Peneliti adalah sebagai instrumen kunci yang dilengkapi dengan instrumen pendukung lainnya berupa panduan observasi, pedoman wawancara, serta panduan studi dokumentasi.

Peneliti melakukan pengamatan langsung terhadap berbagai kegiatan pada subjek penelitian, mengamati, dan mencatat fasilitas serta sarana prasarana yang ada di DPM, GPM, UPM dan Prorgram Studi Pendidikan Usia Dini, keberadaan sumber daya manusia, serta instrumen dan peralatan teknologi informasi dan komunikasi yang dimanfaatkan dalam penerapan sistem penjaminan mutu internal.

Aspek dokumentasi dalam penelitian ini dengan cara mengumpulkan dokumen seperti: surat-surat yang terkit dengan kegiatan SPMI, Pengumunan resmi tentang SPMI, laporan kegiatan pelaksanaan dan monitirng SPMI, artikel-artikel yang berkaitan dengan SPMI, informasi kegiatan SPMI yang ada di lingkungan Universitas Islam Nusantara, dokumen kegiatan, dokumen layanan, dokumen keorganisasian, bagan struktur organisasi, termasuk dokumen anggaran yang berkaitan dengan pelaksanaan sistem penjaminan mutu internal pada UPM dan Program Studi Pendidikan Anak Usia Dini.

\section{HASIL DAN PEMBAHASAN}

Penjaminan mutu pendidikan pada satuan perguruan tinggi merupakan proses penetapan, pelaksanaan, evaluasi, pengendalian dan peningkatan standar mutu pengelolaan pendidikan tinggi secara konsisten dan berkelanjutan, sehingga stakeholders (mahasiswa, dosen, tenaga kependidikan, orang tua, pemerintah, dunia kerja, serta pihak lain yang berkepentingan) memperoleh kepuasan. DPM Universitas Islam Nusantara telah menyusun konsep dan kebijakan sistem penjaminan mutu internal Universitas Islam Nusantara. Konsep dan kebijakan SPMI tersebut meliputi definisi sistem penjaminan mutu, siklus penerapan penjaminan mutu, organisasi, sistem dokumentasi, dan sumber daya manusia.

$$
\text { Universitas Islam Nusantara }
$$
mendirikan organisasi pejaminan mutu yang diberi nama Direktorat Penjaminan Mutu (DPM) pada tanggal 28 Juni 2009, sesuai dengan surat keputusan Rektor Nomor: 47SK/UIN/VI/2009. Sesuai dengan Struktur Organisasi dan Tata Kerja (SOTK), DPM 
Universitas Islam Nusantara berada langsung di bawah rektor. Tugas dan funfsi DPM Universitas Islam Nusantara adalah: 1) Menyusun dan menggembangkan berbagai standar dan pedoman sebagai acuan melaksanakan penjaminan mutu pendidikan, penelitian dan pengabdian kepada masyarakat serta administrasi akademik; 2) Mengembangkan standar mutu dalam bidang pendidikan, penelitian, dan pengabdian kepada masyarakat merujuk standar internasional; 3) Mengkoordinasikan pelaksanaan kegiatan penjaminan mutu pendidikan, penelitian dan pengabdian kepada masyarakat, serta administrasi akademik mulai tingkat universitas sampai program studi; 4) Mengkaji dan melaporakan hasil pelaksanaan penjaminan mutu dalam suatu siklus pada seluruh unit dan jajarannya di Universitas Islam Nusantara; 5) Menyampaikan rekomendasi kepada Rektor dan pimpinan lainnya sebagai masukan untuk peningkatan mutu secara berkelanjutan. DPM Universitas Islam Nusantara dibantu oleh organisasi penjaminan mutu tingkat fakultas/Sekolah Pascasarjana yaitu Gugus Jaminan Mutu (GJM) dan Unit Pernjaminan Mutu (UPM) tingkat Program Studi. Struktur dan Mekanisme SPM Dikti yang ditetapkan dalam Permendikbud No. 50 Tahun 2014 tentang SPM Dikti sebagai berikut: Struktur SPM Dikti. SPM Dikti tersusun dalam suatu struktur yang terdiri atas: a) SPMI, yaitu kegiatan sistemik penjaminan mutu pendidikan tinggi oleh setiap perguruan tinggi secara otonom atau mandiri untuk mengendalikan dan meningkatkan penyelenggaraan pendidikan tinggi secara berencana dan berkelanjutan; b) SPME, yaitu kegiatan penilaian melalui akreditasi untuk menentukan kelayakan program studi dan perguruan tinggi; c) PDDikti, yaitu kumpulan data dan informasi penyelenggaraan pendidikan tinggi seluruh perguruan tinggi di Indonesia yang terintegrasi secara Nasional.

Sistem Penjaminan Mutu Internal (SPMI) adalah kegiatan sistemik penjaminan mutu pendidikan oleh perguruan tinggi untuk mengawasi penyelenggaraan pendidikan tinggi oleh perguruan tinggi itu sendiri secara berkelanjutan untuk kepuasan stakeholders.
Penerapan SPMI di Universitas Islam Nusantara dilaksanakan sebagai sebuah keharusan karena mutu pendidikan tidak hanya tergantung pada pemerintah tetapi juga tergantung pada penilaian para pemangku kepentingan. Penerapan SPMI di Universitas Islam Nusantara merupakan kegiatan mandiri, sehingga proses penjaminan mutu direncanakan, dilaksanakan, dievaluasi, dikendalikan, dan ditingkatkan sendiri tanpa campur tangan pemerintah. Hal ini merujuk pada ketentuan Ditjen Dikti Kemendiknas (2010: 15) yang menyatakan bahwa SPMI di perguruan tinggi dilakukan sepenuhnya oleh perguruan tinggi sendiri, tanpa campur tangan pemerintah.

Penerapan SPMI tingkat Program Studi sebagai bagian integral dari sistem penjaminan mutu pendidikan tinggi di Universitas Islam Nusantara dilaksanakan dengan penyusunan rancangan SPMI yang secara operasional disebut Siklus SPMI Universitas Ialam Nusantara yang dilaksanakan mengikuti periode satu tahunan. Siklus SPMI Islam Nusantara terdiri atas tujuh langkah atau tahap, yaitu: (a) penetapan Standar, (b) pelaksanaan, (c) monitoring, (d) evaluasi diri, (e) audit mutu internal, (f) rumusan koreksi, dan (g) peningkatan mutu. Penetapan standarstandar dirumuskan berdasarkan peraturan perundang-undangan, hasil evaluasi diri tentang kinerja yang sedang berjalan, masukan dari stakeholders, hasil studi pelacakan (tracer study), dan kebijakan pengembangan penjaminan mutu Ditjen Dikti. Standar yang ditetapkan dalam SPMI Universitas Islam Nusantara mengacu pada Standar Nasional Pendidikan (SNP). Tahapan dalam pelaksanaan SPMI di Universitas Islam Nusantara adalah: sosialisasi SPMI; bantuan teknis program studi; sosialisasi audit mutu internal (AMI) dan instrumen evaluasi diri program studi (EDPS), pengisian EDPS; pelaksanaan AMI; tindakan koreksi/tindakan perbaikan; rapat tinjauan manajemen tingkat fakultas/Sekolah Pascasarjana untuk membahas tentang temuan audit dan peningkatan mutu program studi; rapat tinjauan manajemen tingkat universitas, untuk membahas temuan yang diperoleh di program studi yang tidak dapat diselesaikan di tingkat 
program studi; dan fakultas akan dibawa ke tingkat Universitas.

Monitoring bertujuan untuk mengawal Penerapan SPMI yang dilaksanakan berdasarkan rencana. Evaluasi Diri merupakan upaya sistematik untuk menghimpun dan mengolah data (fakta dan informasi) yang handal dan sahih sehingga dapat disimpulkan kenyataan yang dapat digunakan sebagai landasan tindakan manajemen untuk mengelola kelangsungan lembaga, seperti Fakultas/Sekolah Pascasarjana, dan program studi. AMI adalah audit penjaminan dan konsultasi yang independen serta objektif terhadap kegiatan operasional akademik atau proses akademik. Rumusan koreksi didasarkan pada temuan audit mutu intermal yang ditindaklanjuti dengan rapat tinjauan manajemen di tingkat Prodi, Fakultas/Sekolah pascasarjana, dan universitas. Rumusan koreksi selanjutnya akan menjadi bahan untuk mengkaji ulang (review) audit mutu internal berikutnya, apakah sudah ada tindakan perbaikan yang dilakukan. Hasil rumusan koreksi mengarahkan pada peningkatan mutu melalui penetapan standar/perencanaan baru pada tahapan selanjutnya. Peningkatan mutu yang sesungguhnya pada akhirnya akan ditentukan oleh masyarakat sebagai stakeholders eksternal. Peningkatan mutu sebagai dampak penerapan SPMI di Universitas Islam Nusantara secara menyeluruh.

Penerapan SPMI tingkat Program Studi di Universitas Islam Nusantara didukung oleh sumber daya manusia (SDM) yang memiliki kompetensi dalam bidang penjaminan mutu. DPM Universitas Islam Nusantara saat ini memiliki 21 orang tenaga auditor AMI yang aktif yang terdaftar sebagai tenaga auditor. Penerapan SPMI di Universitas Islam Nusantara juga ditunjang dengan pembiayaan yang memadai melalui anggaran yang sudah ditetapkan Kinerja DPM Universitas Islam Nusantara didukung sarana dan prasarana yang memadai dengan menempati bangunan Kantor DPM Universitas Islam Nusantara.

Mutu out-put program studi selain diukur dari pemenuhan setiap Standar Dikti, harus pula diukur dari pemenuhan interaksi antarstandar Dikti untuk mencapai tujuan pendidikan tinggi. Mekanisme SPM Dikti diawali oleh perguruan tinggi dengan mengimplementasikan SPMI melalui siklus kegiatan yang disingkat sebagai PPEPP, yaitu terdiri atas: (1) Penetapan (P) Standar Dikti, yaitu kegiatan penetapan standar yang terdiri atas SN Dikti dan Standar Dikti yang ditetapkan oleh perguruan tinggi; (2) Pelaksanaan (P) Standar Dikti, yaitu kegiatan pemenuhan standar yang terdiri atas SN Dikti dan Standar Dikti yang ditetapkan oleh perguruan tinggi; (3) Evaluasi pelaksanaan Standar Dikti, yaitu kegiatan pembandingan antara luaran kegiatan pemenuhan standar dengan standar yang terdiri atas SN Dikti dan Standar Dikti yang telah ditetapkan oleh perguruan tinggi; (4) Pengendalian (P) pelaksanaan Standar Dikti, yaitu kegiatan analisis penyebab standar yang terdiri atas SN Dikti dan Standar Dikti yang telah ditetapkan oleh perguruan tinggi yang tidak tercapai untuk dilakukan tindakan koreksi; dan (5) Peningkatkan (P) Standar Dikti, yaitu kegiatan perbaikan standar yang terdiri atas SN Dikti dan Standar Dikti agar lebih tinggi daripada standar yang terdiri atas SN Dikti dan Standar Dikti yang telah ditetapkan. mutu dan penetapan standar baru. Kendala Penerapan SPMI karen kurangnya komitmen pimpinan dihadapi dengan cara menyediakan tenaga yang memang expert di bidang penjaminan mutu. Pimpinan yang memiliki multi tugas, baik sebagai pendidik sekaligus sebagai personal penjaminan mutu, dirasakan kurang optimal hasil kerjanya. Kendala kurangnya jumlah tenaga auditor yang dimiliki DPM ditempuh dengan cara memprogramkan pelatihan auditor baru. Program pelatihan auditor baru dan refreshing auditor lama dilaksanakan intensif setiap tahun. Kendala Penerapan SPMI sering terjebak menjadi kegiatan rutinitas dihadapi dengan merefresh dan membangun semangat baik di tataran pimipinan Universitas, Fakultas, dan Program Studi serta para auditor sendiri. DPM Universitas Islam Nusantara juga menciptapkan programprogram yang sifatnya menyadarkan posisi penting penjaminan mutu seperti secara berkala bertemu dalam forum kegiatan penyegaran dan peningkatan mutu auditor. 
Selain itu, interaksi dengan para penggiat penjaminan mutu internal perguruan tinggi dalam forum SPMI Dikti, dan BAN PT.

Penerapan SPMI memerlukan sistem evaluasi untuk menilai efektivitas dari pelaksanaan penjaminan mutu internal tersebut. DPM Universitas Islam Nusantara setiap tahun mengadakan evaluasi, dengan meminta masukan dari para auditor, dari Pimpinan Fakultas/Sekolah pascasarjana dan prodi yang diaudit, dan pimpinan universitas. Evaluasi dilakukan dalam bentuk workshop, yang membahas masukan dan koreksi terhadap pelaksanaan Audit Mutu Internal. Evaluasi Penerapan SPMI selain membahas efektivitas pelaksanaan SPMI juga mengevaluasi bagaimana faktor pendukung dapat memberikan kontribusi yang optimal, seperti faktor pembiayaan, SDM, dan sarana dan prasarana pendukung.

Secara eksternal, hasil Penerapan SPMI dimanfaatkan terkait dengan persiapan dalam menghadapi akreditasi pihak eksternal, dalam hal ini adalah Badan Akreditasi Nasional (BAN PT). DPM Universitas Islam Nusantara juga telah membantu universitas dalam penyusunan Borang akreditasi institusi Badan Akreditasi Nasional Perguruan Tinggi (BAN PT). Pemanfaatan hasil Penerapan SPMI di Universitas Islam Nusantara juga dimanfaatkan untuk persiapan akreditasi.

Penerapan SPMI di Universitas Islam Nusantara didasarkan pada dua dokumen, yaitu Dokumen Akademik dan Dokumen Mutu. Dokumen Akademik yang berada pada tingkat Universitas dan Fakultas/Sekolah Pascasarjana terdiri atas dokumen Kebijakan Akademik, Standar Akademik, dan Peraturan Akademik. Dokumen Akademik di tingkat Program Studi terdiri atas Spesifikasi Program Studi, Kurikulum, Peta Kurikulum, dan Rencana Program dan Kegiatan Pembelajaran Semester (KPS). Dokumen Mutu terdiri atas Manual Mutu pada tingkat Universitas atau Fakultas/Sekolah Pascasarjana, Prosedur Mutu, dan Instruksi Kerja. Prosedur Mutu dan Instruksi Kerja disusun dan dilaksanakan pada masing-masing unit kerja. Dalam penjaminan mutu penelitian dan pengabdian kepada masyarakat, DPM Universitas Islam Nusantara melakukan pendampingan untuk memastikan bahwa semakin banyak jurnal di Universitas Islam Nusantara. Penjaminan mutu penelitian juga terkait dengan mutu laboratorium yang dimiliki Universitas Islam Nusantara. Rancangan SPMI yang secara operasional disebut Siklus SPMI Universitas Islam Nusantara dikembangkan sejalan dengan model manajemen kendali mutu model Kaizen. Kendala Penerapan SPMI sering terjebak menjadi kegiatan rutinitas dihadapi dengan merefresh dan membangun semangat baik di tataran Pimipinan Universitas, Fakultas/Sekolah Pascasarjana, dan Program Studi serta para auditor sendiri. DPM Universitas Islam Nusantara juga menyusun program-program yang sifatnya menyadarkan posisi penting penjaminan mutu seperti secara berkala bertemu dalam forum kegiatan penyegaran dan peningkatan mutu auditor. Selain itu, interaksi dengan para penggiat penjaminan mutu internal perguruan tinggi dalam forum SPMI Dikti, dan BAN-PT Program tersebut diarahkan guna meningkatakan kesadaran dalam rangka membangun budaya mutu.

Penerapan SPMI secara internal dimanfaatkan untuk peningkatan mutu pendidikan secara bertahap. Temuan-temuan dalam penerapan SPMI akan dijadikan masukan untuk memperbaiki standar dan meningkatkan menjadi lebih baik lagi. Pmanfaatan hasil Penerapan SPMI selain digunakan dalam perencanaan pendidikan, juga digunakan untuk menumbuhkan semangat bekerja lebih baik lagi.

\section{PENUTUP}

Konsep dan kebijakan SPMI di Universitas Islam Nusantara diartikan sebagai suatu proses yang berkelanjutan dalam peningkatan mutu proses pendidikan melalui kegiatan penetapan, pelaksanaan, evaluasi, pengendalian dan peningkatan, kemudian dilakukan evaluasi diri, audit mutu internal, sampai dengan benchmarking untuk menentukan standar baru, yang disebut sebagai siklus penjaminan mutu. Pengorganisasian SPMI di Universitas Islam Nusantara dilakukan oleh organisasi penjaminan mutu yang diberi nama Direktorat Penjaminan Mutu Universitas Islam Nusantara (DPM-UNINUS) yang bertugas untuk merencanakan dan melaksanakan sistem 
penjaminan mutu secara utuh dan menyeluruh. Penerapan SPMI di Universitas Islam Nusantara dilaksanakan dengan penyusunan rancangan SPMI yang secara operasional disebut Siklus SPMI yang dilakukan mengikuti periode satu tahunan. Siklus SPMI terdiri atas tujuh langkah atau tahap, yaitu: penetapan standar, pelaksanaan, monitoring, evaluasi diri, audit mutu internal, rumusan koreksi, dan peningkatan mutu untuk kepuasan stakehorders.

Kendala yang dihadapi dalam penerapan SPMI di Universitas Islam Nusantara termasuk pada tingkat Program Studi adalah: komitmen pimpinan relatif kurang, jumlah tenaga auditor yang masih terbatas, kegiatan SPMI sering terjebak menjadi kegiatan rutin. Langkah yang ditempuh menghadapi kendala: menyediakan tenaga yang expert di bidang penjaminan mutu, memprogramkan pelatihan auditor baru dan refreshing auditor lama dilaksanakan intensif, membangun semangat baik Pimipinan Universitas, Fakultas/Sekolah Pascasarjana, dan Program Studi. Evaluasi Penerapan SPMI di Universitas Islam Nsantara dilakukan setiap tahun, dengan meminta masukan dari para auditor, dari pimpinan Fakultas/Sekolah Pascasarjana dan prodi yang diaudit, dan Pimpinan Universitas.

Pemanfaatan hasil Penerapan SPMI di Universitas Islam Nusantara secara internal untuk peningkatan mutu pendidikan, menumbuhkan semangat bekerja lebih baik, membangkitkan kesadaran untuk membangun budaya mutu. Secara eksternal dimanfaatkan terkait dengan persiapan dalam menghadapi akreditasi oleh BAN-PT. Pengembangan Penerapan SPMI di Universitas Islam Nusantara mengacu pada Sistem Manajemen Mutu yang mendukung penerapan standar Badan Akreditasi Nasional Perguruan Tinggi (BAN PT) sebagai standar minimal pengelolaan program studi dan universitas.

\section{KEPUSTAKAAN ACUAN}

Ditjen Dikti Depdiknas. (2003). Pedoman penjaminan mutu (quality assurance) pendidikan tinggi. Jakarta: Ditjen Dikti Depdiknas.

Ditjen Dikti Depdiknas. (2004). Strategi jangka panjang pendidikan tinggi (HELTS) 2003
2010 menuju sinergi kebijakan nasional. Jakarta: Ditjen Dikti Depdiknas.

Ditjen Dikti Kemendiknas. (2010). Sistem penjaminan mutu perguruan tinggi (SPMT). Jakarta: Ditjen Dikti Kemendiknas.

Hedwig, R. \& Polla, G. (2006). Model sistem penjaminan mutu dan proses penerapannya di perguruan tinggi. Yogyakarta: Graha Ilmu.

Kemendiknas. (2009). Permendiknas Nomor 63, Tahun 2009, tentang sistem penjaminan mutu pendidikan.

Macdonald, J. (2005). Understanding total quality management in a week, London: St Edmundsbury Press.

Markum, M.E. (2007). Pendidikan tinggi dalam perspektif sejarah dan perkembangannya di Indonesioa, Jakarta: Direk-torat Jenderal Pendidikan Tinggi Departemen Pendidikan Nasional.

Oakland, J.S. (1995). Total quality management: The route to improving performance, London: Butterworth-Heine-mann Ltd.

Presiden. (2005). Peraturan Pemerintah RI Nomor 19, Tahun 2005, tentang standar nasional pendidikan.

Republik Indonesia. (2003). Undang-undang RI Nomor 20, Tahun 2003, tentang sistem pendidikan nasional.

Republik Indonesia. (2012). Undang-undang Nomor 12, Tahun 2012, tentang pendidikan tinggi.

Reynolds, L. (1994). Beyond total quality management. Great Britian: Sheldon Press.

Tampubolon, D.P. (2001). Perguruan tinggi bermutu perguruan, paradigma baru manajemen pendidikan inggi menghadapi tantangan abad 21. Jakarta: Gramedia Pustaka Utama.

Tjiptono, F. \& Diana, A. (2000). Total quality management. Yogyakarta: Andi Offset.

Wijatno, S. (2009). Pengelolaan perguruan tinggi secara efisien, efektif, dan ekonomis untuk meningkatkan mutu penyelenggaraan pendidikan dan mutu lulusan. Jakarta: Salemba Empat.

Yin, R. K. (2013). Case study reasearch: Design \&methods. California: Sage Publications, Inc. 